\title{
Design of Active Fractional PID Controller Based on Whale's Optimization Algorithm for Stabilizing a Quarter Vehicle Suspension System
}

\author{
Zeyad Abdulwahid Karam, Osama A. Awad ${ }^{1}$ \\ ${ }^{1}$ Systems Engineering Department, College of Information Engineering, Al-Nahrain University, P. O. B. 64046, 64074 Baghdad, Iraq \\ * Corresponding author, e-mail: zyad.karam@coie-nahrain.edu.iq
}

Received: 28 August 2019, Accepted: 18 December 2019, Published online: 24 February 2020

\begin{abstract}
Improving the dynamic performance of an automobile suspension system is considered as the main demand for comfortable and safe passenger travelling. From all previously proposed and implemented works, it is noticed that there are other factors that need to be considered to raising the car holding and stability in the road for improved passenger comfort when travelling. The minimization of car body displacement and oscillation time after exposure to road disturbances have been adopted in this work due to their contribution in raising the car holding and stability. The improvement in these features was maintained via a robust control methodology. The Fractional Order PID controller tuned by the Whales Optimization Algorithm (WOA) and Particle Swarm Optimization (PSO) algorithm is suggested in this work as a robust controller to reduce the effect of these demerits. In this paper, an active quarter car suspension nonlinear system is designed for the presented goals using a robust controller. Minimizing the displacement of the car body and reducing the damping frequency are achieved via a nonlinear control strategy using the fractional order PID controller, which can maintain the required characteristics. Tuning the parameters of the FOPID controller is performed by using the Whales Optimization Algorithm (WOA). Robustness of the FOPID controller is examined and proved to withstand a system parameter variation of $\pm 12 \%$ in all system parameters and a maximum of $\pm 80 \%$ in controller parameter variation. Simulation outcomes also indicate a considerably improved performance of the active suspension system with the fractional order PID controller over the traditional PID. Keywords
\end{abstract}

quarter car suspension system, FOPID controller, PSO algorithm, WOA algorithm

\section{Introduction}

In the last decade, the development of car systems takes a large scope and interest according to the relation of the active trade cars market. Suspension systems are regarded as the most important factor in vehicle design, which is highly related to passenger comfort and car stability. As an essential part of the vehicle's body, a quarter suspension system is attached to each wheel. It is assembled from four parts: a tyre, a spring, a linkage, and a damper as a shock absorber. The design of an old suspension system is composed of a spring, damper, and mass, also known as a passive suspension system. Many car manufacturers designed the suspension system with specific control stability criteria to raise passenger comfort and ride stability. The designed systems can handle the minimum range of road peaks (road bumps) and pits; with these ranges, the car body will be subjected to oscillations after this road disturbance that results in an uncomfortable travel and unstable ride.

The active car suspension system was proposed by many manufacturers to handle these passive suspension drawbacks. The active system of hydraulic actuator with a piston rod between the car body and some points of suspension system structure to overcome the car body deflection (oscillation) after exposing to different disturbances that are related to road postures. One of the main issues associated with active car suspension systems is the need for a robust control strategy that can control the hydraulic actuator to achieve optimal controlled suspension system characteristics with the presence of model uncertainty, some parameter variations, and/or inaccurate feedback measurements. 
Many works in the past decade were accomplished in order to design, model, and control the active suspension system. Kumar, attempted to develop an active car suspension system using the traditional PID control to achieve improved dynamic characteristics in suspension system deflection. Controller tuning was conducted using the Zeigler and Nichols method [1].

Two creative works were accomplished in 2010, the first one proposed by Aldair and Wang [2], where a full vehicle nonlinear active suspension system was modelled and controlled by a Fractional Order PID (FOPID). The controller was designed, and parameters were optimized using Genetic Algorithm (GA). The outcome manifested the efficiency of the suggested controller. The second study was presented by Pekgökgöz et al. [3], in which a fuzzy logic controller was examined to control an active car suspension system of a quarter model. The Genetic Algorithm was applied to optimize the membership function distribution within the universe of discourse of the fuzzy controller. The proposed Fuzzy PID controller provided performance over the PID controller for minimizing the ultimate body deflection.

Nagarkar et al. [4], presented good analyses to passive and active suspension systems, controlled by utilizing the Linear Quadratic Regulator (LQR) approach. The LQR controller displayed a better achievement for compartment riding in comparison to the passive suspension system.

In 2012 another two remarkable studies were performed by Mouleeswaran [5], where the active suspension system improvement was achieved by considering the frequency analysis for the rode disturbances imposed on the system. The tests showed the applicability of the PID control as an active mechanism. The second study was proposed by Goga and Klúčik [6], where a mathematical model for the half-car suspension system was developed. The passive suspension system parameters were optimized by the GA. The outcome showed the improvement of inactive system performance.

Aly and Salem [7] modelled an automatic quarter car suspension system controlled using fuzzy controller FLC to improve vehicle stability for any road disturbance that interrupts the ride. The drawn conclusion showed that FLC is more efficient than the classical approach.

An adaptive control strategy was used to track the rode disturbances while keeping the car driving stability. The proposed adaptive controllers considered a novel strategy for controlling nonlinear models presented by Sun et al. $[8,9]$.
In 2013, Yao et al. [10] proposed a combined model reference control system with sliding mode control that was designed to be easily implemented. The determination of the sliding mode control is achieved so that the error dynamics between the reference model and the plant states were asymptotically stable.

Two studies for controlling the active suspension system, using the $\mathrm{H}_{\infty}$ method, reported on the design robust controllers minimizing the control stability criteria to maintain the stable ride and comfort proposed by Guo et al. [11], and by Wang et al. [12]. Ozer et al. [13] proposed an optimized Sliding Mode Controller (SMC) tuned by using the Genetic Algorithm for a half suspension vehicle model. The proposed SMC improves ride passenger comfort and car stability.

Drehmer et al. [14] determined the parameters of the suspension system for a frequency domain vehicle model subjected to diversified road profiles such that a multi-objective function is minimized. The programming of sequential quadratic and Particle Swarm Optimization algorithms are utilized to establish the optimal parameters of a suspension system in accordance with various velocity situations and road profiles.

The control strategy of an additive actuator was proposed by Dong et al. [15], where a combined nonlinear model of a quarter car suspension system and actuator of electro-hydraulic type was implemented. The FOPID control was designed and implemented to manipulate the displacement of the actuator. The results showed that FOPID controller parameters performed better than the PID controller.

Deshpande et al. [16] proposed an active suspension system that satisfies the objectives of both an improved comfort in riding and, at the same time, keeping the deflection in suspension system bounded by the boundary of the rattle space. The proposed approach relied on a new nonlinear disturbance compensator for the suspension deflection.

A creative work is proposed by Concilio et al. [17]. Here they developed a variable geometry car suspension system which was designed to be simple in construction, small in size, requires minimum energy for its implementation, and can be installed without substantial changes to the original passive suspension system through retrofitting operations. The device was applied to a vehicle computer-aided design model.

Another good work is initiated by Fu et al. [18], where a quarter car active suspension system is designed by an optimal adaptive control approach. The Approximate Dynamic Programming algorithm (ADP) is applied. 
The proposed methodology presented an improved performance when exposing to unknown road displacement.

Xue et al. [19] proposed a suspension system using FiniteTime Stability (FTS) control combined with H-infinity controller. The stability of input-output finite-time to the bound of $\mathrm{H}_{\infty}$ with an appropriate term that guarantees the mixture of IO-FTS/ $\mathrm{H}_{\infty}$ behavior for a linearized system was presented. The proposed control strategy was proved via simulation.

From all the works that were proposed and implemented in the past, it is noticed that there are other factors that need to be considered for raising the car holding and stability in the road with passengers travelling comfort. The minimum car body displacement and minimum oscillation time after exposing to road disturbances (cusp or holes) have a contribution in raising the car holding and stability. These extra active suspension system characteristics can be achieved by using a robust control methodology to satisfy the required characteristics. The FOPID controller tuned by Particle Swarm Optimization (PSO) and the Whales Optimization Algorithm (WOA) is suggested in this work and showed to produce an optimized controller that maintains these characteristics.

The remaining sections of this article are arranged as follows: in Section 2, the mathematical model and the Simulink modelling of the nonlinear active car suspension system are detailed. In Section 3, the FOPID controller is presented. The hybrid PID and FOPID controllers tuned by Particle Swarm Optimization (PSO) are designed and tested in Section 4. In Section 5, PID and FOPID controllers tuned by the Whales Optimization Algorithm (WOA) are designed and simulated. The system modelling is implemented by MATLAB Simulink. In Section 6, the simulation results of each controller are displayed. Section 7 summarizes the percentage of enhancement in system performances compared to previously tackled works. Finally, the robustness tests for the proposed controllers are discussed and conclude in Sections 8 and 9 respectively.

\section{Model and simulation of the active quarter car suspension system}

The traditional engineering system for dissipating car wheel disturbance is designed by involving two elements, a spring and a damper. These two parts are combined into structuring passive suspension systems. The design of the suspension system provides a compromise between the stability of the vehicle and the ride comfort.

Fig. 1 summarizes this relation when ride comfort increases at low damping with vehicle stability and vice versa at high damping. The car suspension system is

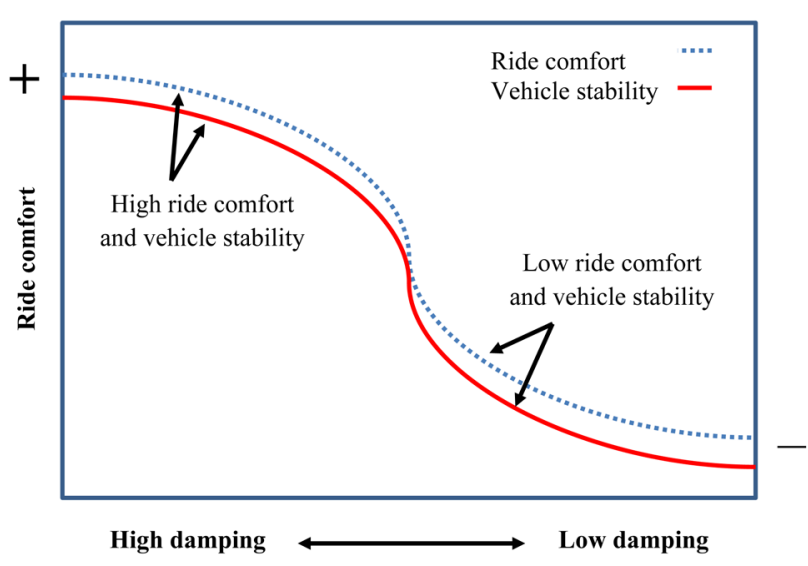

Fig. 1 Parameter compromise graph for a passive suspension system [7]

developed based on two conflicting objectives of passive springs and dampers. Therefore, many models have been designed and tested to improve the car holding and stability in the road.

The design of the active suspension system includes the insertion of a hydraulic-servo actuator that can be controlled electrically by a controllable servo valve. The inserted actuator is structured by connecting it between the body of the car and the wheel mass. The actuator then performs the control on the displacement between the body and the wheel as the last is deflected due to road disturbances. The acceleration of system masses is measured by sensors, then feeding it back as analogue signals to the controller. The controller will take the optimum action to leverage the efficiency of the system by dissipating the cusp actions through stroke retract or the holes action through stroke extrusion. The controlled signal is amplified and fed to the actuator, such that the required force is generated between the car body and the wheel mass. Fig. 2 illustrates the schematic representation of the closed-loop active car suspension system [5] and [7]. The active suspension system is dynamically represented by the following Eqs. (1) and (2) [5, 7]:

$$
\begin{aligned}
& m_{s} \ddot{X}_{s}+ K_{s}\left(X_{s}-X_{u s}\right)+C_{a}\left(\dot{X}_{s}-\dot{X}_{u s}\right)-u_{a}=0 \\
& m_{u s} \ddot{X}_{u s}+K_{s}\left(X_{u s}-X_{s}\right)+C_{a}\left(\dot{X}_{u s}-\dot{X}_{s}\right) \\
&+K_{t}\left(X_{u s}-Z_{r t}\right)+u_{a}=0 .
\end{aligned}
$$

The parameters of a quarter active suspension system with respect to the static equilibrium position, as given by $[5,7]$ are shown in Table 1 .

Fig. 3 shows the Simulink model of a quarter active car suspension system.

The state-space representation of Eqs. (1) and (2) becomes: $\dot{X}_{1}=X_{2}$, 


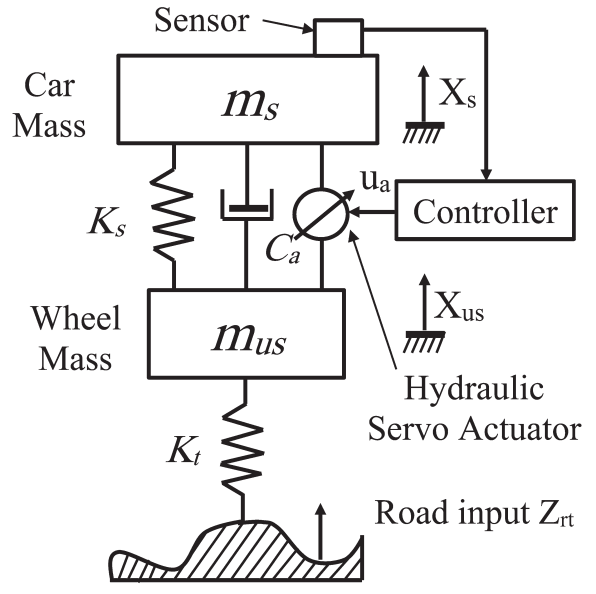

Fig. 2 Quarter car active suspension system schematic diagram [5]

Table 1 Parameters of a quarter active car suspension system [5, 7]

\begin{tabular}{lcc}
\hline Symbol & Parameter & Value and Units \\
\hline$m_{s}$ & Car body mass (one quarter) & $250 \mathrm{~kg}$ \\
$m_{u s}$ & Wheel mass & $50 \mathrm{~kg}$ \\
$K_{s}$ & Body spring stiffness & $16812 \mathrm{~N} / \mathrm{m}$ \\
$K_{t}$ & Wheel spring stiffness & $190000 \mathrm{~N} / \mathrm{m}$ \\
$C_{a}$ & The damping ratio of the damper & $1000 \mathrm{~N} \cdot \mathrm{sec} / \mathrm{m}$ \\
$u_{a}$ & Desired cylinder force to be & $\mathrm{N}$ \\
$X_{u s}$ & delivered & $\mathrm{M}$ \\
$X_{s}$ & Car wheel displacement & $\mathrm{M}$ \\
$Z_{r t}$ & Car body displacement & $\mathrm{m}$ \\
$\beta$ & Input road displacement & $1 \mathrm{sec}{ }^{-1}$ \\
$A$ & Effective bulk modulus & $0.0075 \mathrm{~m}$ \\
$\omega$ & Area of the chamber & - \\
$t$ & spool valve area gradient & $\mathrm{sec}$ \\
$U$ & Time & $10,10] \mathrm{Volt}$ \\
$P_{s}$ & Control signal & $10.55 \mathrm{MPa}$ \\
\hline & Suplied pressure & \\
\hline & &
\end{tabular}

$\dot{X}_{2}=-1 / m_{s}\left[K_{s}\left(X_{1}-X_{3}\right)+C_{a}\left(X_{2}-X_{4}\right)\right]+A / m_{s} X_{5}$,

$\dot{X}_{3}=X_{4}$,

$\dot{X}_{4}=-1 / m_{u s}\left[K_{s}\left(X_{1}-X_{3}\right)+C_{a}\left(X_{2}-X_{4}\right)+K_{t}\left(X_{3}-Z_{r t}\right)\right]$ $+A / m_{s} X_{5}$

$\dot{X}=\beta X_{5}+A\left(X_{2}-X_{4}\right)+X_{6} \omega$,

$\dot{X}=\frac{X_{6}}{t} U$,

$\omega=\operatorname{sgn}\left[P_{s}-\operatorname{sgn}\left(X_{6}\right) * X_{5}\right] \sqrt{\left|P_{s}-\operatorname{sgn}\left(X_{6}\right) * X_{5}\right|}$, where $X_{1}=X_{s}, X_{2}=\dot{X}_{s}, X_{3}=X_{u s}, X_{4}=\dot{X}_{u s}, X_{5}$ is the pressure inside the chamber of hydraulic piston and $X_{6}$ is the valve displacement.

\section{FOPID controller}

In 1999, Podlubny [20] introduced the concept of the FOPID controller. The primary difference between a PID and FOPID controller is that the order of integral and derivative in the FOPID is non-integer. This enhancement led to the generation of a nonlinear PID controller. By depending on this attribute, the extra degrees of freedom in obtaining the tuned parameters leads to the utmost dynamic performance of the FOPID in comparison to the conventional PID controller as presented by Tepljakov et al. [21] and by Taher et al. [22]. The control of fractional order is considered the core in modelling fractional-order systems. The operator of non-integer-order is fundamentally given by:

$a D_{t}^{\alpha}= \begin{cases}\frac{d^{\alpha}}{d t^{\alpha}} & (\alpha>0), \\ 1 & \alpha=0, \quad \alpha \in Z, \\ \int_{a}^{t}(d \tau)^{-\alpha} & \alpha<0 ;\end{cases}$

where $t$ and $a$ represent the operation boundaries. The $\alpha$ refers to traditional integration or differentiation. Many definitions work out for the generalized operator. Tepljakov et al. [23] provides the following definition:

$\alpha D_{t}^{\alpha} f(t)=\frac{1}{\Gamma(m-\alpha)}\left(\frac{d}{d t}\right)^{m} \int_{a}^{t} \frac{f(\tau)}{(t-\tau)^{\alpha-m+1}} d \tau$,

where $\Gamma($.$) represent the Euler's gamma function for$ $m-1<\alpha<m, m \in N$. Also the Grunwald-Letnikov representation is considered due to its importance for a numerical evaluation in the applications of fractional derivatives:

$\alpha D_{t}^{\alpha} f(t)=\lim _{h \rightarrow 0} \frac{1}{h^{\alpha}} \sum_{j=0}^{[t-a / h]}(-1)^{j}\left(\begin{array}{c}\alpha \\ j\end{array}\right) f(t-j h)$.

If $a$ is equal to zero and $t$ is equal to the steps computational index $k$ times the step size $h$, then the Laplace transform of the fractional $\alpha$-order derivative with the assumption of zero initial conditions is given by

$\int_{0}^{\infty} e^{-s t} \alpha D_{t}^{\alpha} f(t) d t=s^{\alpha} F(s)$,

where $\alpha \in R+$ and $s$ is the complex variable defined by $(\sigma+j \omega)$, representing the variable of Laplace transformation. The fractional $\mathrm{PI}^{\lambda} \mathrm{D}^{\mu}$ controller in parallel form structure is given by Eq. (14): 


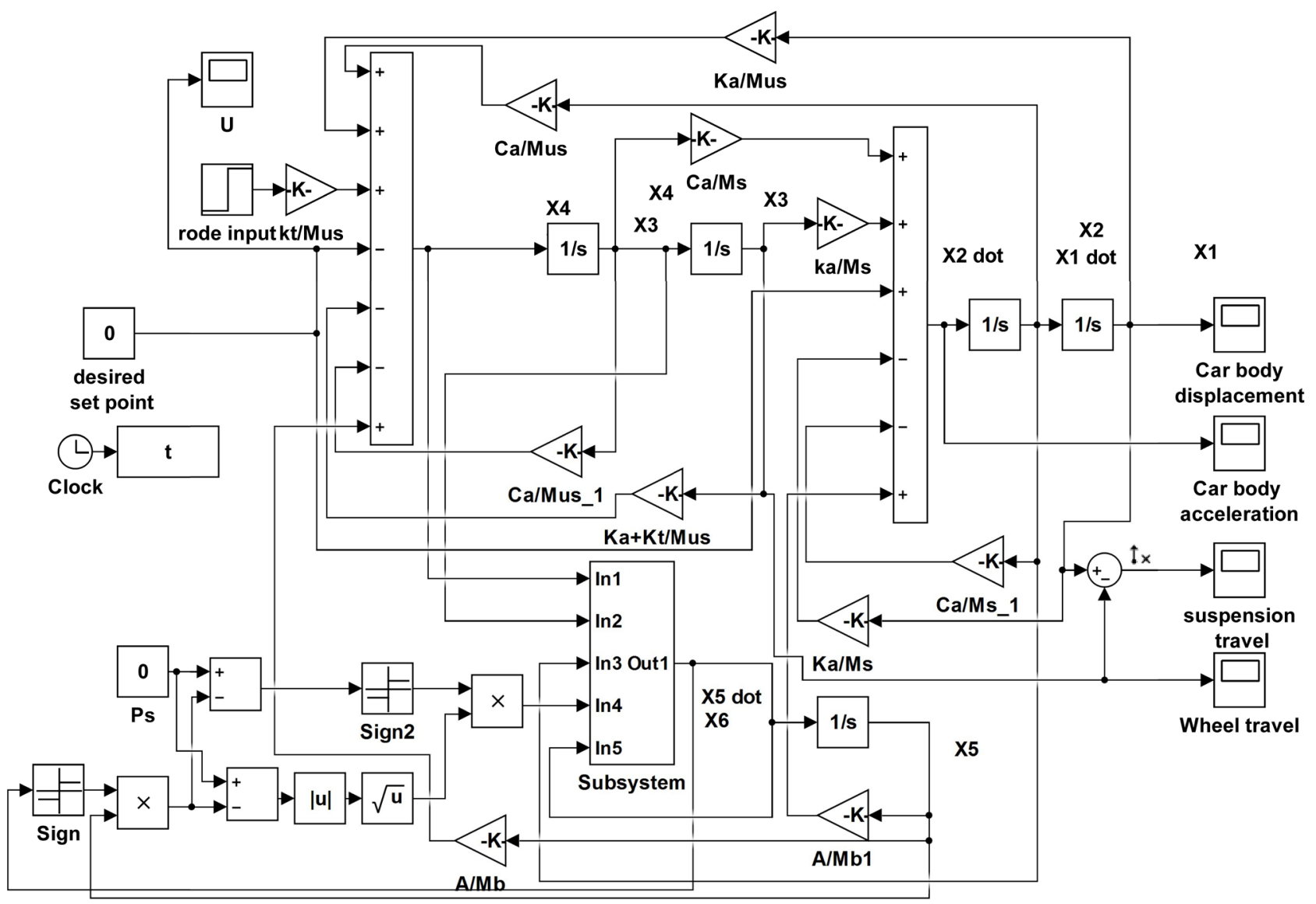

Fig. 3 Simulink model for active quarter car suspension system

$C_{\mathrm{FOPID}}(s)=K_{p}+K_{i} / s^{\lambda}+K_{d} s^{\mu}$

where $K_{p}, K_{i}$, and $K_{d}$ correspond, respectively, to the gains of proportional, integral, and derivative terms. Also $\mu$ and $\lambda$ are the orders of derivative and integral, respectively. If $\mu$ and $\lambda$ are unity then the classical PID controller will be obtained, otherwise, the fractional PID is deduced. Each one of these controllers is a special case from the $\mathrm{PI}^{\lambda} \mathrm{D}^{\mu}$ controller. The FOPID controller is very flexible in tuning its gains, which leads to better adjustments in the dynamical properties of the controlled system [21], also presented by Choudhary [24] and by Anantachaisilp and Lin [25].

Fig. 4 represents the parallel structure of the FOPID control block diagram.

The efficiency and accuracy are considered, and an appropriate approximation method is proposed for that reason which is based on suitable frequency-domain in the manner of Oustaloup recursive filter approximation.

Fractional-order operator $s^{\gamma}$, where $0<\gamma<1$, in a bounded frequency range $\omega=\left(\omega_{b}, \omega_{h}\right)$ with $N$ order by a rationalistic transfer function obtained as following:

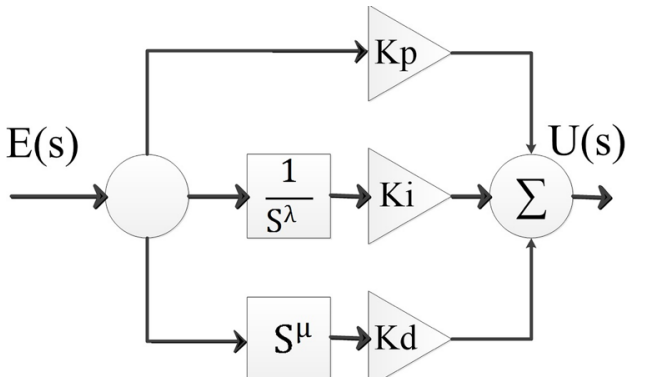

Fig. 4 The block diagram of FOPID controller [25]

$s^{\gamma}=K \prod_{k=-N}^{N} \frac{s+\omega_{k}^{\prime}}{s+\omega_{k}}$

where the gain, poles, and zeros are obtained accordingly by the following:

$$
\begin{aligned}
& \omega_{k}^{\prime}=\omega_{b}\left(\omega_{r}\right) \frac{k+N+\frac{1}{2}(1-\gamma)}{2 N+1}, \\
& \omega_{k}=\omega_{b}\left(\omega_{r}\right) \frac{k+N+\frac{1}{2}(1+\gamma)}{2 N+1}, \\
& K=\omega_{h}^{\gamma}, \omega_{r}=\frac{\omega_{h}}{\omega_{b}} .
\end{aligned}
$$


A modified Oustaloup method provides results of high approximation in term of frequency range:

$$
s^{\gamma}=G_{\omega} \prod_{k=-N}^{N} \frac{s+\omega_{k}^{\prime}}{s+\omega_{k}},
$$

where

$$
\begin{aligned}
& G_{\omega}=\left(\frac{d \omega_{h}}{b}\right)^{\gamma}\left(\frac{d s^{2}+b \omega_{h} s}{d(1-\gamma) s^{2}+b \omega_{h} s+d \gamma}\right), \\
& \omega_{k}=\left(\frac{b \omega_{h}}{d}\right)^{\frac{\gamma+2 k}{N+1}}, \omega_{k}^{\prime}=\left(\frac{d \omega_{b}}{b}\right)^{\frac{\gamma-2 k}{2 N+1}},
\end{aligned}
$$

where $b>0$ and $d>0$. Optimal results can be found with $b=10$ and $d=9$, so the parameters are fixed based on these values [25].

Due to the commutative peculiarity of the fractional operator $s^{\alpha}$, the order $\alpha \geq 1$ will approximated by

$s^{\alpha}=s^{n} s^{\gamma}$,

where $n=\alpha-\gamma$ represents the integer part of $\alpha$ and by the Oustaloup approximation $s^{y}$ obtained by using Eqs. (12) and (13). As a note, the resulting order can be very high due to system interconnection of approximation while the order of the resulting filter in the illustrated cases is $2 N+1$.

This straiten the using of the method to computer numerical solutions. Therefore, through using the described approximations, the issue of the simulating fractional and integer-order mixed structure systems is solved.

\section{Particle Swarm Optimization algorithm (PSO)}

The Particle Swarm Optimization algorithm will be used as an offline tuning algorithm to establish the five controller parameters for the FOPID $\left(K_{p}, K_{i}, K_{d}, \lambda\right.$, and $\left.\mu\right)$. The population in PSO is constructed from particles. Each flying particle moves around in a velocity searching the multidimensional space. The location and velocity of each particle are continuously updated according to its own experience and according to the experience of the neighboring particles or the whole swarm. The application of this algorithm is successfully exercised in many fields. It is widely applied in optimizing nonlinear functions, classifying patterns, training of artificial neural networks, and tuning of controllers in different control systems. The PSO algorithm is performed in the following ways summarized by Hassan and Karam [26] and by Alfi and Fateh [27]:

1. The population size is constructed from $n$ particles, each particle representing the collection of the parameters to be optimized.

2. Initial populations of particles are randomly selected.

3. Each particle is examined against a specified objective function to find its fitness.
4. The parameters to be optimized are updated continuously while the search is directed towards its minimized objective function.

5. The optimal previous position pbest ${ }_{i}$ and the optimal global position gbest of each particle is evaluated for the entire population at each step of computing. Eventually, particles are flying to the optimal locations within the available searching universe. The $i$-th particle velocity $v_{i}$ is calculated by [25]:

$$
v_{i}(k+1)=\chi\left[\begin{array}{l}
v_{i}(k)+c_{1} r_{1}\left(\text { pbest }_{i}(k)-x_{i}(k)\right) \\
+c_{2} r_{2}\left(\text { gbest }-x_{i}(k)\right)
\end{array}\right],
$$

where $i$ is the particle index and $k$ is the iteration index. $\left(x_{i}\right)$ is the position, which represents the controller parameter, (pbest $t_{i}$ ) is the previous optimal position, and (gbest) is the previous global optimal position of particles. The acceleration coefficients $\left(c_{1}, c_{2}\right)$ are the cognitive and social scaling parameters which affect improving both a faster convergence for the algorithm as well as easement of trapping in the local minima. $r_{1}$ and $r_{2}$ are two random numbers in the range of [0 to 1]. The constriction coefficient $\chi$ is given by $[28,29]$ :

$$
\chi=2 /\left|4-\phi-\sqrt{\phi^{2}-4 \phi}\right|,
$$

where the constriction coefficient is bounded by the particles convergence which is satisfying the following:

$$
\phi=c_{1}+c_{2}, \quad \forall \quad \phi>4 .
$$

Hence, convergence is ensured, and an explosion is prevented. The new $i$-th particle location is calculated by [25] and [29]:

$$
x_{i}(k+1)=x_{i}(k)+v_{i}(k+1) \text {. }
$$

The proposed fitness function used in evaluating the particles is based on the overshoot and the Root Mean Squared Error (RMSE) in position responses. The balancing weight of the two objectives is manually adjusted, and the fitness function $F$ is given by

$$
F=0.95\left(\operatorname{RMSE}_{k}\right)+0.05\left(\text { overshoot }_{k}\right) \text {. }
$$

The RMSE is calculated using the following equation:

$\operatorname{RMSE}=E(k)=\frac{1}{N} \sum_{i=1}^{N} \sqrt{e^{2}(i)}$,

where $N$ is referring to the maximum number of samples, $k$ is the iteration index, and is the error in suspension travel for the $i$-th sample. The designed controllers required 
a faster response to provide its action, so the force range for the control signal is $[-40,40] N$, and that can achieved with MOOG servo valves.

The conventional PID controller equation of MATLAB module is [30]:

$$
C_{\mathrm{PID}}(s)=K_{p}+K_{i} / s+K_{d} N / 1+N \frac{1}{s},
$$

where $N$ is the first order filter coefficient.

\section{Whales Optimization Algorithm (WOA)}

The WOA will be used as an offline tuning algorithm for the controller parameters. The WOA was first introduced by Mirjalili and Lewis [31]. WOA is a meta-heuristic naturally inspired optimization algorithm. It emulates the humpback whales in their social life. The bubble-net is the strategy of hunting in the algorithm. Nature-inspired meta-heuristic approaches are used as an optimization solver by copying either the natural biological or physical phenomena. It can be recognized as an organization from three main categories: natural inspiration from physics, swarm-based algorithms, and evolution inspiration. Evolution algorithms are derived from the laws of the natural reproduction of the phenomena. Physics methods emulate the physical phenomena rules in nature.

The swarming methods have noticeable advantages when compared with the evolution methods. These advantages include the swarming algorithms maintain the information of the searching space over posterior iterations while evolution algorithms drop the old saved information when the new one is created for the new population. The behavior involves the random best search agent to chase the prey and spiral to simulate the mechanism of bubble-net attack of humpback whales. Humpback whales have a special intelligent approach in hunting. This intelligent action of the feeding mechanism is named as bubble-net. The humpback whales favor hunting groups of krill or small fishes near to the surface. This foraging behavior is performed by generating various bubbles along a spiral shape to circulate the prey. Fig. 5 shows the hunting process for the humpback whales.

Humpback whales recognize and circle the prey location. Firstly the optimum position in the searching space is not recognized in advance, so the assumption given to the Whales algorithm regarding the present best position is assumed as the aiming prey or very near to its optimized value. In accordance with finding the agent of the best search, the positions of the other search agents will change towards finding the best search agent. The representation

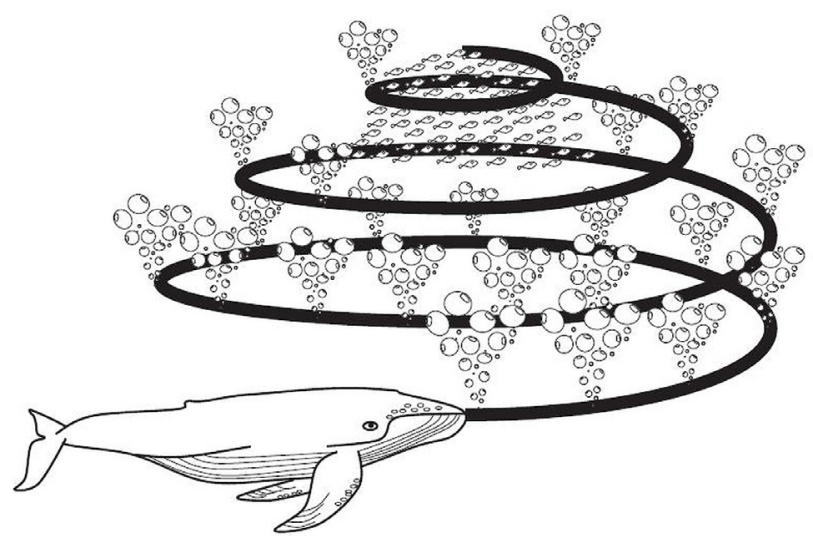

Fig. 5 Hunting process of Bubble-net feeding for humpback whales [32]

of this behavior is achieved via the following equations, Mafarja and Mirjalili [32]:

$\vec{D}=\left|\vec{C} \cdot \vec{X}^{*}(t)-\vec{X}(t)\right|$,

$\vec{X}(t+1)=\vec{X}^{*}(t)-\vec{A} \cdot \vec{D}$,

where the current iteration is represented by $t, \vec{C}$ and $\vec{A}$ are the coefficient vectors, $\vec{X}^{*}$ is the best candidate obtained so far for the position vector, which represent the controller parameters, $\vec{X}$ is the position vector. It is important to note that $\vec{X}^{*}$ should be updated at each iteration until finding the best solution. The vectors $\vec{A}$ and $\vec{C}$ are evaluated by

$\vec{A}=2 \vec{a} \cdot \vec{r}-\vec{a}$,

$\vec{C}=2 \cdot \vec{r}$,

where $\vec{a}$ is to be decreased linearly from 2 to 0 and $\vec{r}$ is a vector randomly chosen in $[0,1]$. The behavior of the circling mechanism is accomplished by decreasing the rate of $\vec{a}$ in Eq. (26). The range of fluctuation in $\vec{A}$ is also changed by decreasing $\vec{a}$. As a result, $\vec{A}$ is a random value bounded by the interval of $[-2,0]$. The values for $\vec{A}$ are set in the range $[-1,1]$. The new search agent position can be assumed anywhere between the agent's original position and the agent's current best position.

The position is updated in a spiral form by calculating the distance between the location of the prey and the whale. The equation of the spiral movement is then created between these positions as follows:

$\vec{X}(t+1)=\vec{D}^{\prime} \cdot e^{b l} \cdot \cos (2 \pi l)+\vec{X}^{*}(t)$,

where $\vec{D}^{\prime}=\left|\vec{X}^{*}(t)-\vec{X}(t)\right|$ indicates the distance of the $i$-th whale to the prey (best solution obtained so far), $b$ is a constant for the shape of a logarithmic spiral, $l$ is a random value in the range $[-1,1]$. An assumption of a $50 \%$ probability is 
made between the spiral model and shrinking circling mechanism to update the whale's position through optimization. The mathematical modelling then is given by $[31,32]$ :

$$
\vec{X}(t+1)=\left\{\begin{array}{lll}
\vec{X}^{*}(t)-\vec{A} \cdot \vec{D} & \text { if } & p<0.5 \\
\vec{D}^{\prime} \cdot e^{b l} \cdot \cos (2 \pi l)+\vec{X}^{*}(t) & \text { if } & p \geq 0.5
\end{array},\right.
$$

where $p$ is a random number in $[0,1]$.

The variation of the $\vec{A}$ vector approach can be utilized for prey exploration. The searching behavior of the humpback whales is random with respect to the position of each other. The $\vec{A}$ vector with the random values limited with ranges greater than 1 or less than -1 makes the search agent move far away from the initial whale position. The exploration is confirmed by letting $|\vec{A}|>1$ with the presented spiral mechanism and WOA is released to start the global search using the following equation:

$\vec{D}=\left|\vec{C} \cdot \overrightarrow{X_{\text {rand }}}-\vec{X}\right|$

$\vec{X}(t+1)=\overrightarrow{X_{\text {rand }}}-\vec{A} \cdot \vec{D}$,

where $\overline{X_{\text {rand }}}$ is a random whale selected from the current population to starting with randomly generated solutions. Searching agents at each iteration begin to update their positions based on a randomized selection of search agents or via the so far optimum solution reached. To keep providing a wide range of exploration, the parameter is lowered from 2 to 0 . A search agent is randomly selected when $|\vec{A}|>1$. On the other hand, the best solution is selected when $|\vec{A}|<1$ to update the position of the search agents. Depending on the $p$-value, WOA has the ability to toggle between the circular and spiral movements. As a final step, WOA is ended by the fulfilment of a certain stopping criterion.

\section{Controlled model simulation and results}

In this work, the quarter active car suspension system will be tested via two controllers: the PID and the FOPID. The PSO or WOA is used as tuning approach to evaluate the optimum parameters for the PID and FOPID controllers. The PSO and WOA will run in an offline mode, thus the time of computation is not critical as in real-time control. In PSO or WOA the largest enhancements in the controlled system are achieved when the fitness function reaches its possible lowest value. Fig. 6 shows the block diagram for the PSO or WOA-based controller.

The fitness function used with PSO and WOA algorithms is mentioned in Eq. (21). The algorithms are simulated offline with the active suspension system using PID and FOPID controllers. Fig. 7 shows the controlled active suspension system model using FOPID.

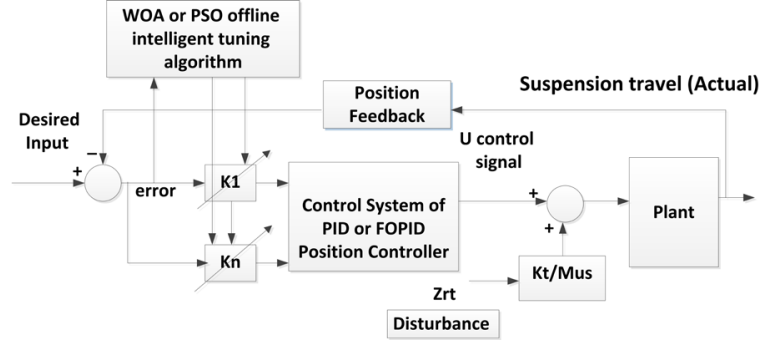

Fig. 6 PID-PSO based controller block diagram [33]

In this work two controllers will control the active suspension system of Eqs. (3) to (9), the conventional linear PID controller and by its nonlinear counterpart using the FOPID example. The simulation results of the active suspension system with the proposed controllers will be examined for the following:

- Conventional PID controller tuned by using the PID auto tuner of MATLAB.

- Conventional PID tuned by the PSO algorithm.

- Conventional PID tuned by the WOA.

- FOPID tuned by PSO.

- FOPID tuned by WOA.

Each optimization algorithm will adapt the FOPID controller parameters in a parallel way. At first, the initial parameters are randomly selected, then, each set of parameters are tested by the objective function. Comparing the objective function for the minimum with the old one, the search is directed to the best solution. The optimization algorithm will update the parameters and continue searching for the best candidates until a stopping criterion based on a predefined iteration limit is reached. Finally, the controller parameters corresponding to the optimal solution by the algorithm are determined. The PSO and WOA parameters are adjusted and adapted according to the objective function as given by Eq. (21).

\subsection{PID controller using the PID MATLAB autotuner}

The closed-loop system is initially tested with the PID controller tuned by the PID autotuner of MATLAB toolbox, and the result is shown in Fig. 8.

It is clear that the output position of the active suspension system is not acceptable as it shows high oscillations with large overshoot.

\subsection{Conventional PID tuned by PSO algorithm}

The PID auto tuner is insufficient to produce an acceptable controller for the active suspension system. Hence, a more sophisticated approach is needed to refine the controller parameters to produce an optimum reaction. 


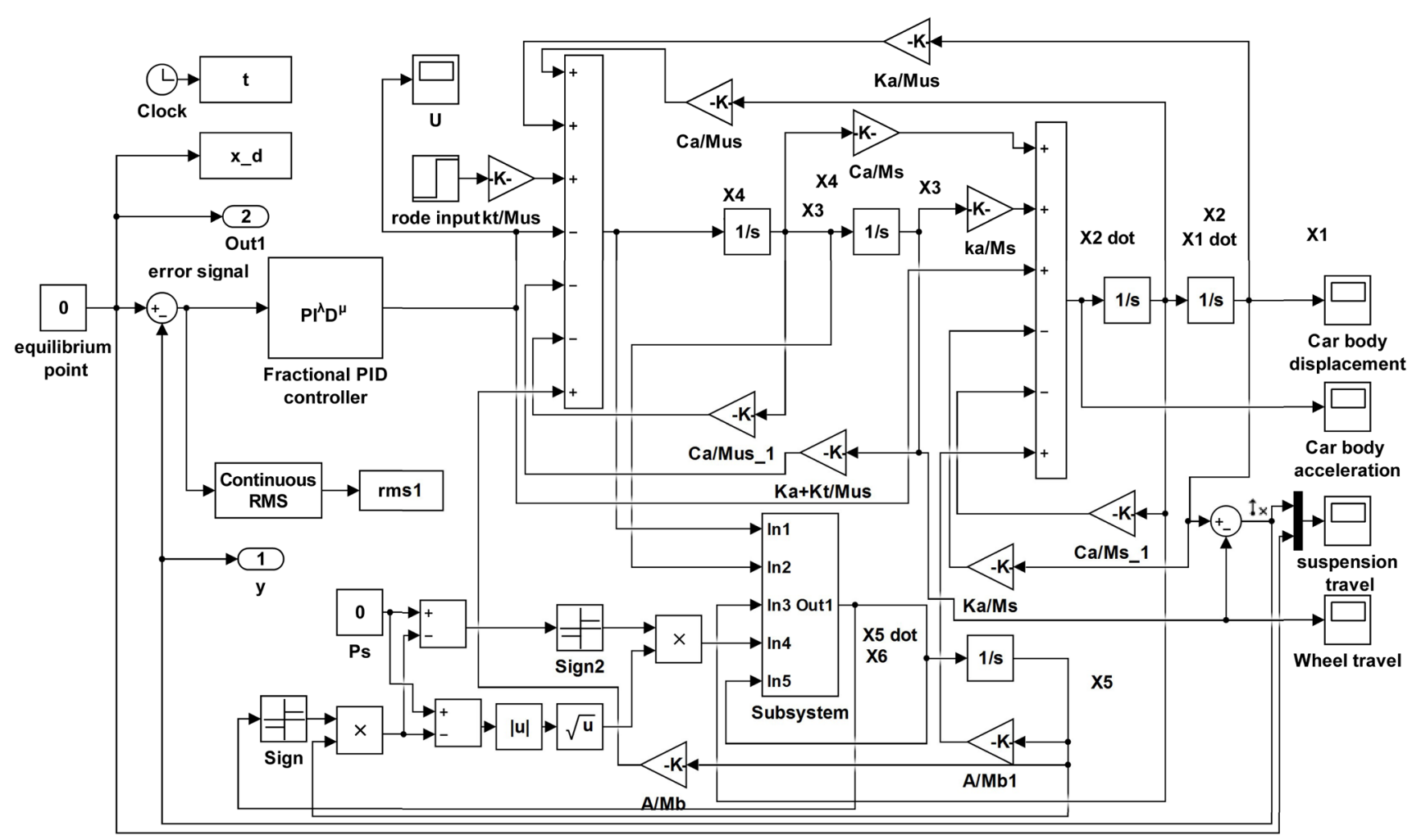

Fig. 7 Simulink model of quarter car suspension system with FOPID controller

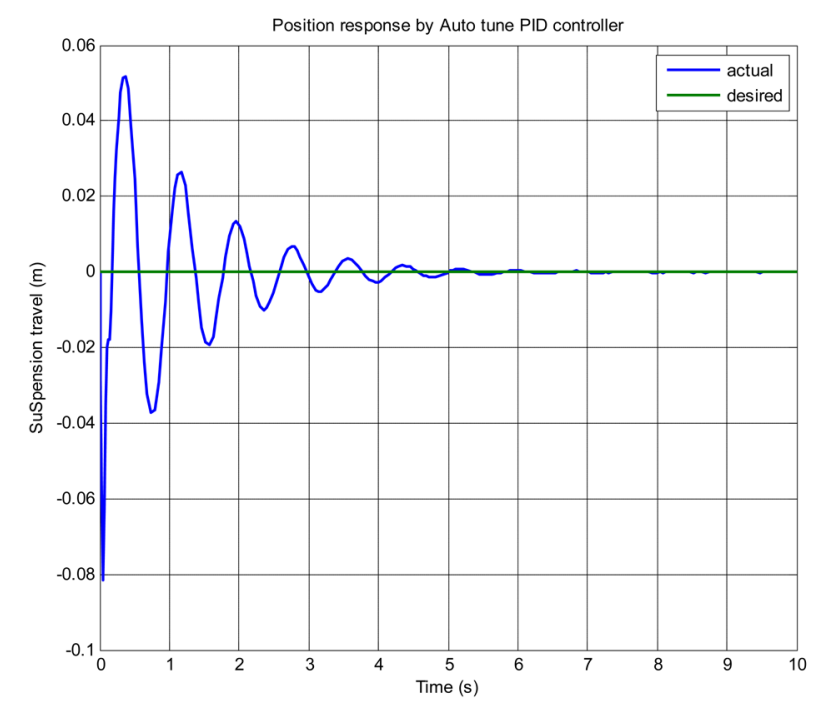

Fig. 8 Car body displacement for road input $Z r t=0.1 \mathrm{~m}$

Two evolutionary algorithms are examined to optimize the PID controller, the PSO, and the WOA. When the PSO algorithm is used with the parameters of Table 2. The PID controller parameters are established as shown in Table 3. (The results are the best out of 25 trials according to the used fitness function.) Eq. (21), gives the fitness function exercised for evaluating the solutions.
Table 2 Experiments for the PID-PSO based controller

\begin{tabular}{lccccc}
\hline Trial & $\begin{array}{c}\text { Global } \\
\text { Fitness } \\
\text { using PID } \\
\text { based PSO }\end{array}$ & $\begin{array}{c}\text { C1 } \\
\text { Cognitive } \\
\text { factor }\end{array}$ & $\begin{array}{c}\text { C2 } \\
\text { Social } \\
\text { scaling } \\
\text { factor }\end{array}$ & $\begin{array}{c}\text { Number of } \\
\text { Iterations }\end{array}$ & $\begin{array}{c}\text { Number } \\
\text { of birds }\end{array}$ \\
\hline 1 & 0.0057 & 3 & 2.7 & 40 & 150 \\
2 & 0.0055 & 2.9 & 2.5 & 45 & 200 \\
\hline
\end{tabular}

Table 3 Gains obtained by the PSO algorithm for the PID controller

\begin{tabular}{lcccc}
\hline Gains & $K_{p}$ & $K_{i}$ & $K_{d}$ & $\begin{array}{c}N \text { Filter } \\
\text { coefficient }\end{array}$ \\
\hline First trial & 0.3490 & 1.1181 & 11.1617 & 100 \\
Second trial & 5.4231 & 1.4585 & 7.7787 & 100 \\
\hline
\end{tabular}

From Table 2, the second trail gives the best global fitness value with convergence as given by Fig. 9 the suspension travel position response and its control signal are shown in Fig. 10 and Fig. 11 respectively.

\subsection{Conventional PID tuned by WOA algorithm}

When the WOA algorithm is used to refine the PID controller parameters, more than 25 experiments have been tested and the best two trials, according to their fitness 


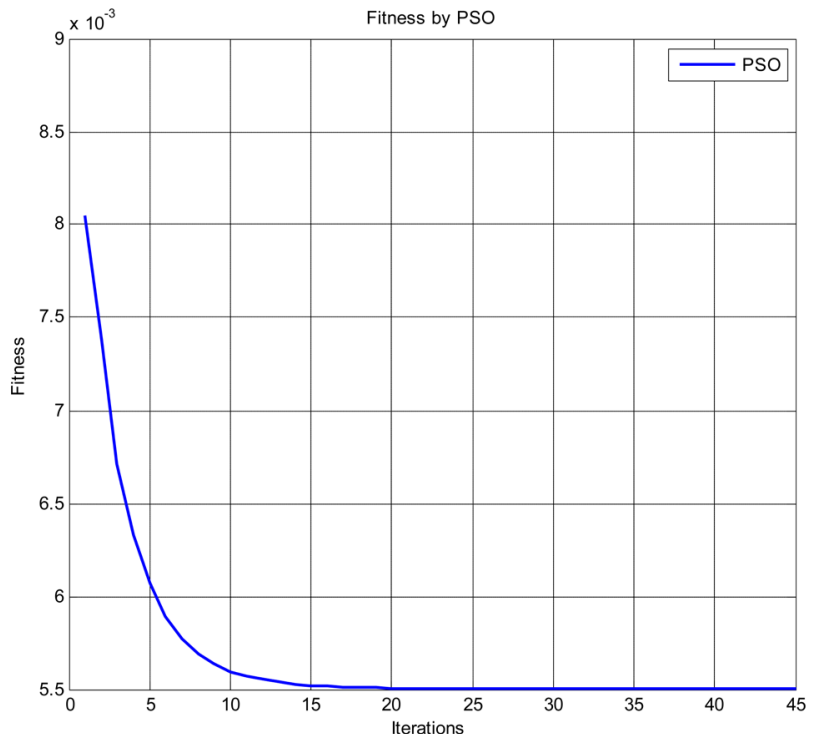

Fig. 9 PSO fitness convergence for the PID controller

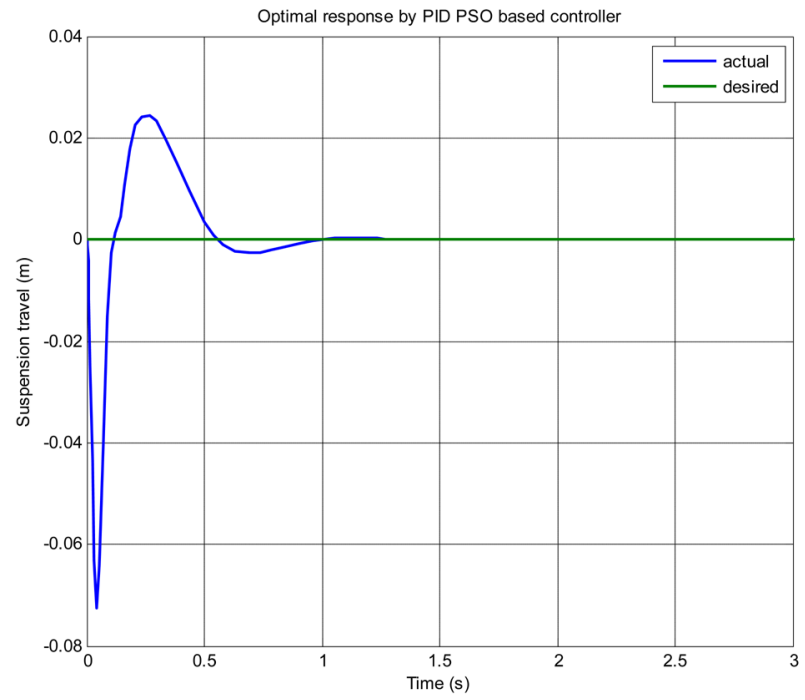

Fig. 10 Car body displacement for road input $Z r t=0.1 \mathrm{~m}$

level, are shown in Table 4. The obtained controller parameters are shown in Table 5.

From Table 4, the second trail gives the best global fitness, and its convergence is given by Fig. 12 the suspension travel position response and its control signal are presented in Fig. 13 and Fig. 14, respectively.

\subsection{FOPID controller tuned by PSO}

The FOPID controller tuned by the PSO is designed for the active suspension system. The fitness functions for the best two trials out of 25 experiments are shown in Table 6 . The tuned controller parameters are shown in Table 7.

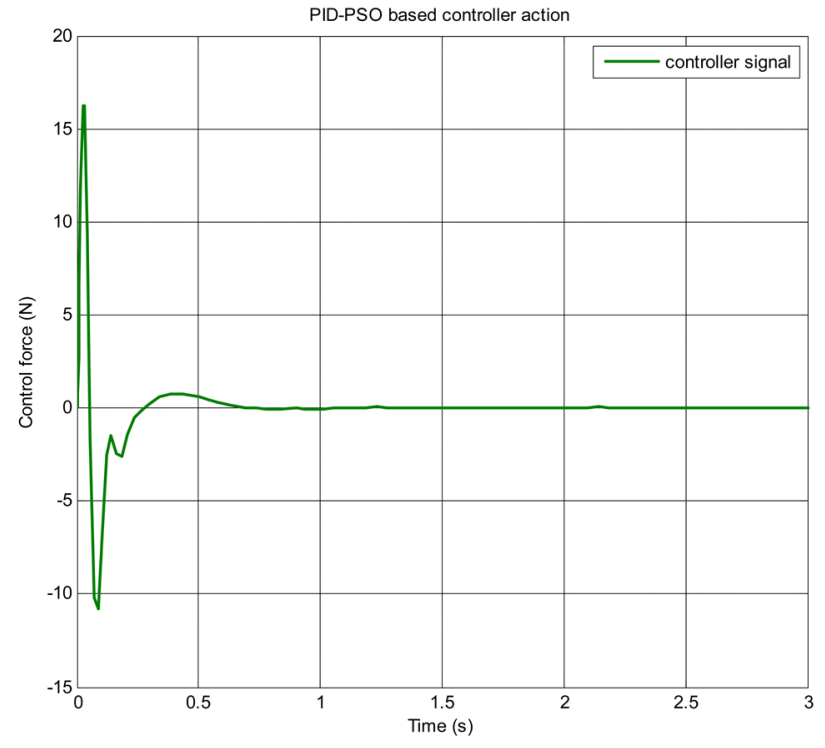

Fig. 11 PID-PSO based control signal

Table 4 Experiments for the PID-WOA based controller

\begin{tabular}{lccc}
\hline Trial & $\begin{array}{c}\text { Global Fitness using } \\
\text { PID based WOA }\end{array}$ & $\begin{array}{c}\text { Number of } \\
\text { Iterations }\end{array}$ & $\begin{array}{c}\text { Number of Search } \\
\text { Agents }\end{array}$ \\
\hline 1 & 0.0053408 & 30 & 1000 \\
2 & 0.0039555 & 50 & 500 \\
\hline
\end{tabular}

Table 5 Gains obtained by the WOA algorithm for the PID controller

\begin{tabular}{lcccc}
\hline Gains & $K_{p}$ & $K_{i}$ & $K_{d}$ & $N$ Filter coefficient \\
\hline First trial & 0.000117 & 0.000609 & 20 & 149.9814 \\
Second trial & 0 & 0.016381 & 20 & 100 \\
\hline
\end{tabular}

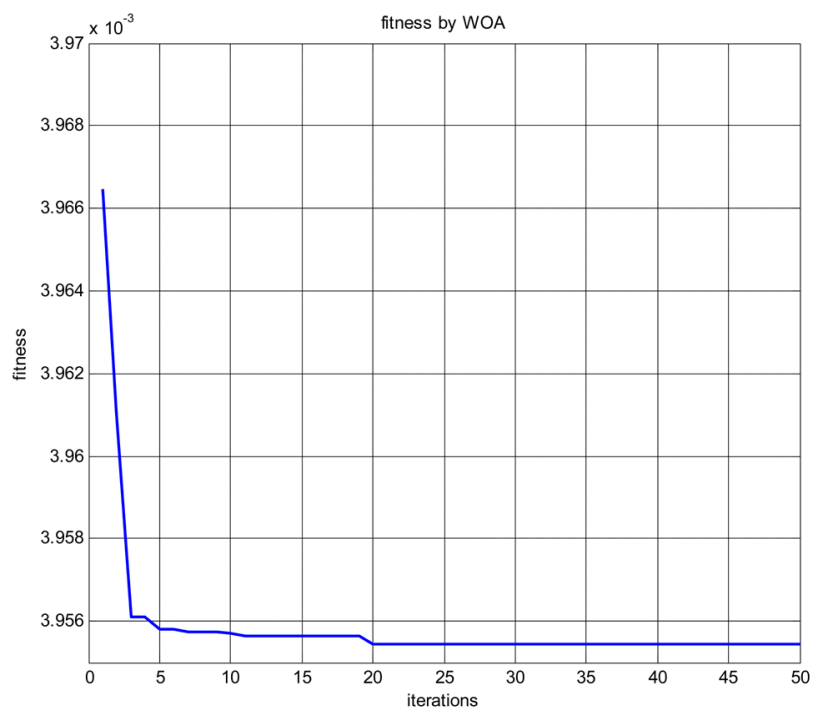

Fig. 12 Fitness obtained by the WOA algorithm for the PID controller 


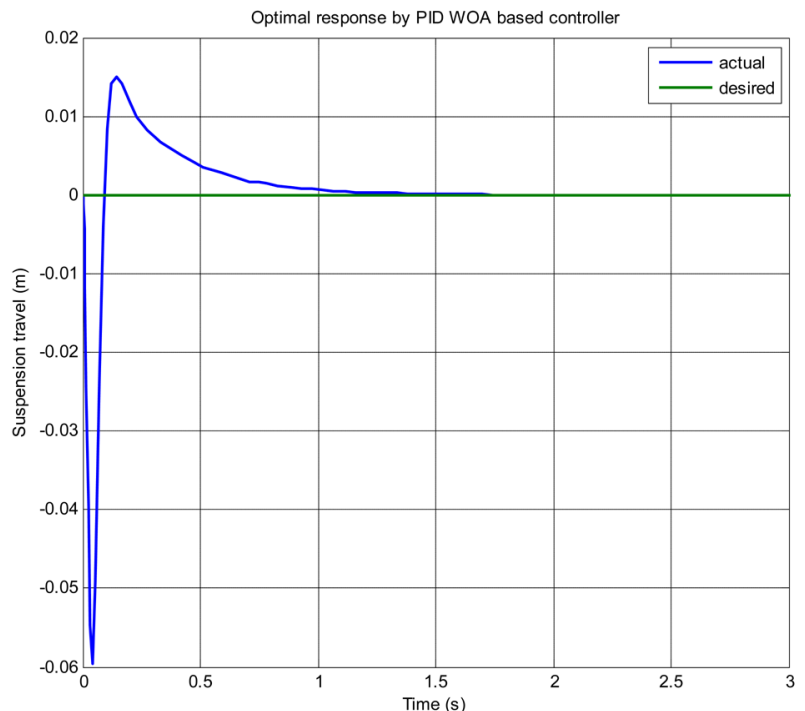

Fig. 13 Car body displacement for road input $Z r t=0.1 \mathrm{~m}$

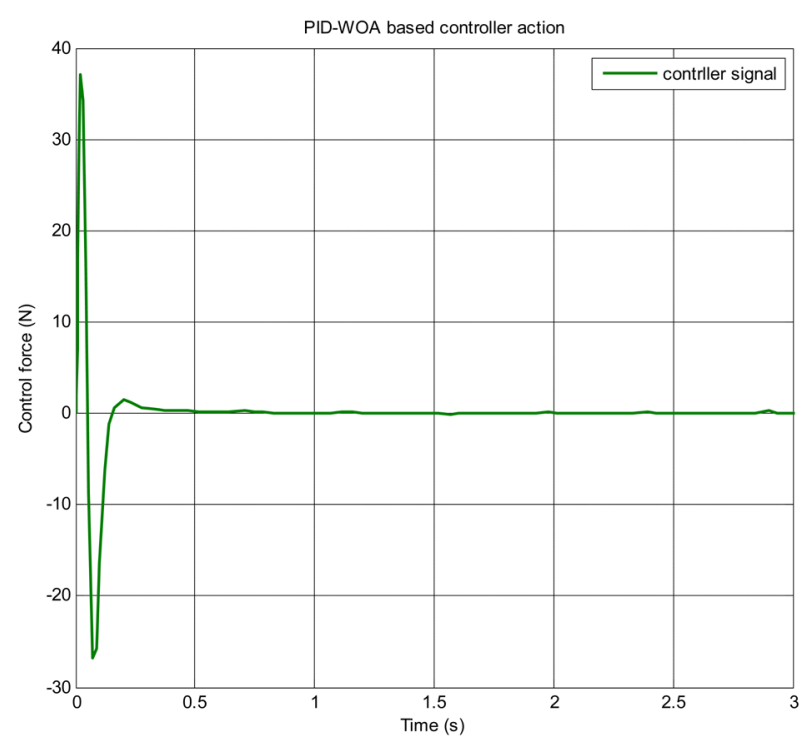

Fig. 14 PID-WOA based control signal

Table 6 Experiments for the FOPID-PSO based controller

\begin{tabular}{lccccc}
\hline Trial & $\begin{array}{c}\text { Global } \\
\text { Fitness } \\
\text { using PID } \\
\text { based PSO }\end{array}$ & $\begin{array}{c}\mathrm{C} 1 \\
\text { Cognitive } \\
\text { factor }\end{array}$ & $\begin{array}{c}\text { C2 } \\
\text { Social } \\
\text { scaling } \\
\text { factor }\end{array}$ & $\begin{array}{c}\text { Number of } \\
\text { Iterations }\end{array}$ & $\begin{array}{c}\text { Number } \\
\text { of birds }\end{array}$ \\
\hline 1 & 0.0041 & 2.9 & 2.7 & 40 & 150 \\
2 & 0.0034 & 3 & 2.6 & 30 & 180 \\
\hline
\end{tabular}

Table 7 Gains obtained by the PSO algorithm for the FOPID controller

\begin{tabular}{lccccc}
\hline Gains & $K_{p}$ & $K_{i}$ & $\lambda$ & $K_{d}$ & $\mu$ \\
\hline First trial & 1.2337 & 2.5642 & 0.5805 & 7.1316 & 1.2587 \\
Second trial & 1.7114 & 0.5950 & 0.9015 & 11.7206 & 0.9727 \\
\hline
\end{tabular}

The controller with the second trial is the optimum one, the PSO fitness convergence is depicted in Fig. 15 The suspension travel position responses with its control signal are presented in Fig. 16 and Fig. 17, respectively.

\subsection{FOPID controller tuned by WOA}

The active suspension system is designed by using the FOPID controller and tuned by the WOA. The fitness function for the best two trials out of 25 experiments is shown in Table 8. The controller parameters are shown in Table 9.

The FOPID controller with the second trial is the optimal one, the WOA fitness convergence is given by Fig. 18 .

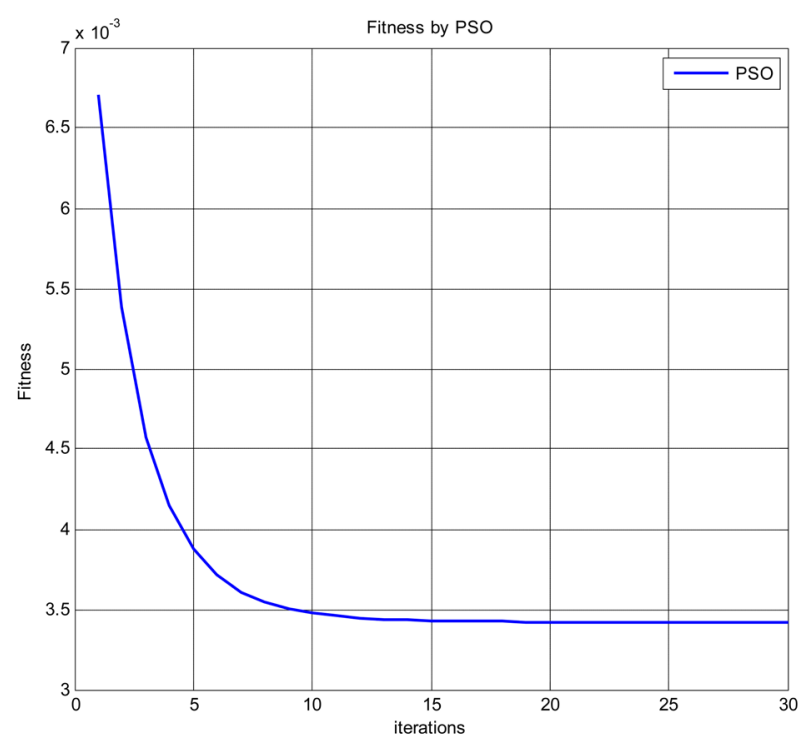

Fig. 15 Fitness obtained by the PSO algorithm for the FOPID controller

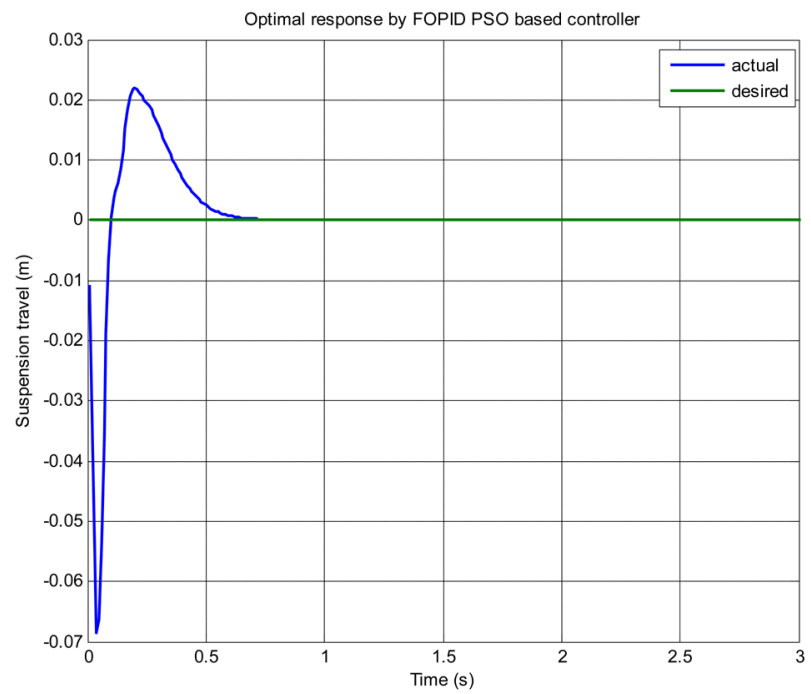

Fig. 16 Car body displacement for road input $Z r t=0.1 \mathrm{~m}$ 


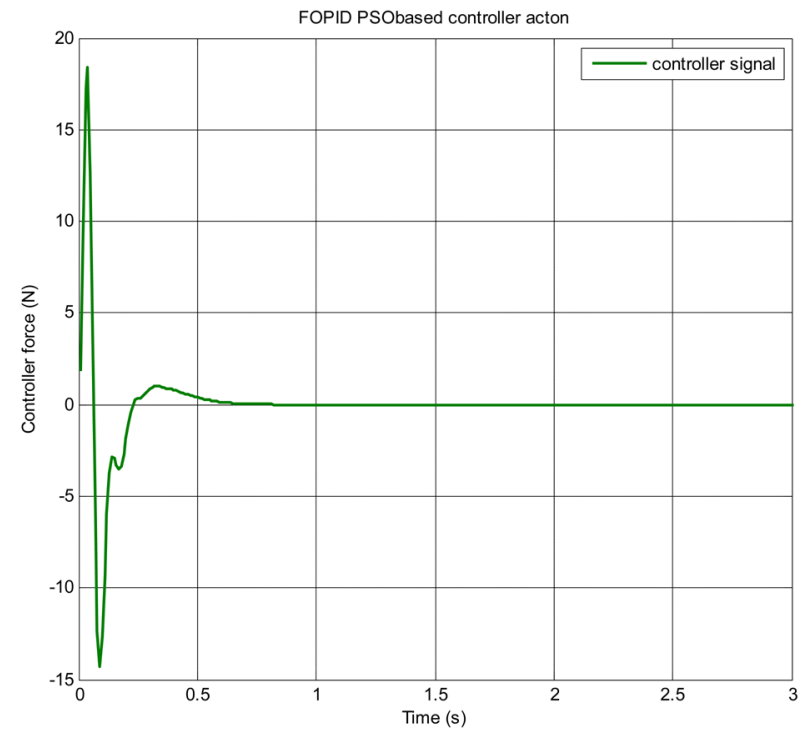

Fig. 17 FOPID-PSO based control signal

Table 8 Experiments for the FOPID-WOA based controller

\begin{tabular}{cccc}
\hline Trial & $\begin{array}{c}\text { Global Fitness by } \\
\text { FOPID_WOA based }\end{array}$ & $\begin{array}{c}\text { Number of } \\
\text { Iterations }\end{array}$ & $\begin{array}{c}\text { Number of } \\
\text { Search Agents }\end{array}$ \\
\hline 1 & 0.001869 & 12 & 35 \\
2 & 0.001736 & 15 & 20 \\
\hline
\end{tabular}

Table 9 Gains obtained by the WOA algorithm for the FOPID controller

\begin{tabular}{lccccc}
\hline Gains & $K_{p}$ & $K_{i}$ & $K_{d}$ & $\lambda$ & $\mu$ \\
\hline First trial & 1.3590 & 13.9481 & 14 & 0.31805 & 0.95873 \\
Second trial & 0.9521 & 14.6932 & 13.8755 & 0.05942 & 1.0585 \\
\hline
\end{tabular}

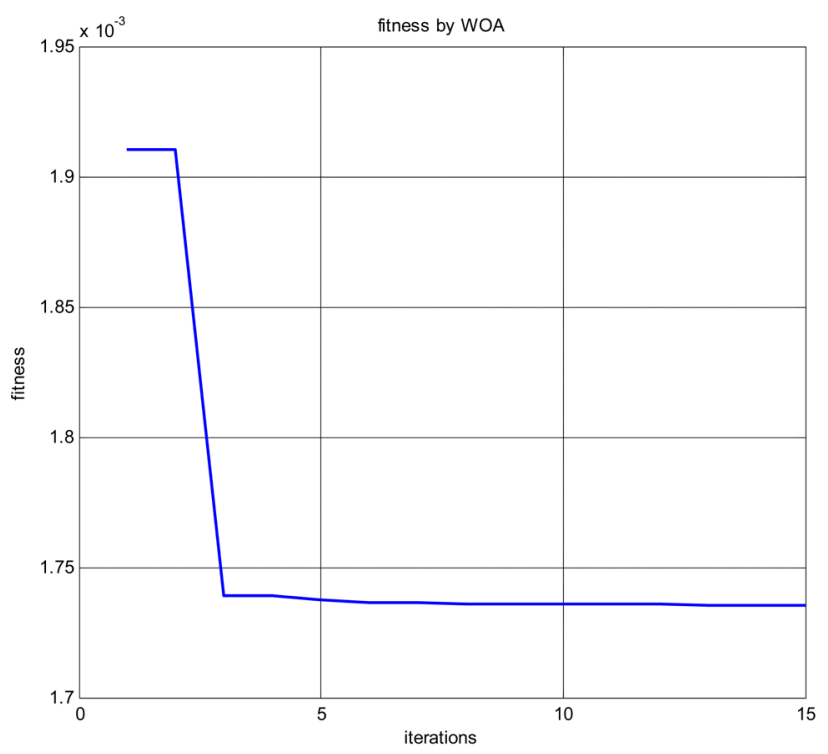

Fig. 18 Fitness obtained by the WOA algorithm for FOPID controller

The response of the suspension travel position with its control signal is presented in Fig. 19 and Fig. 20, respectively.

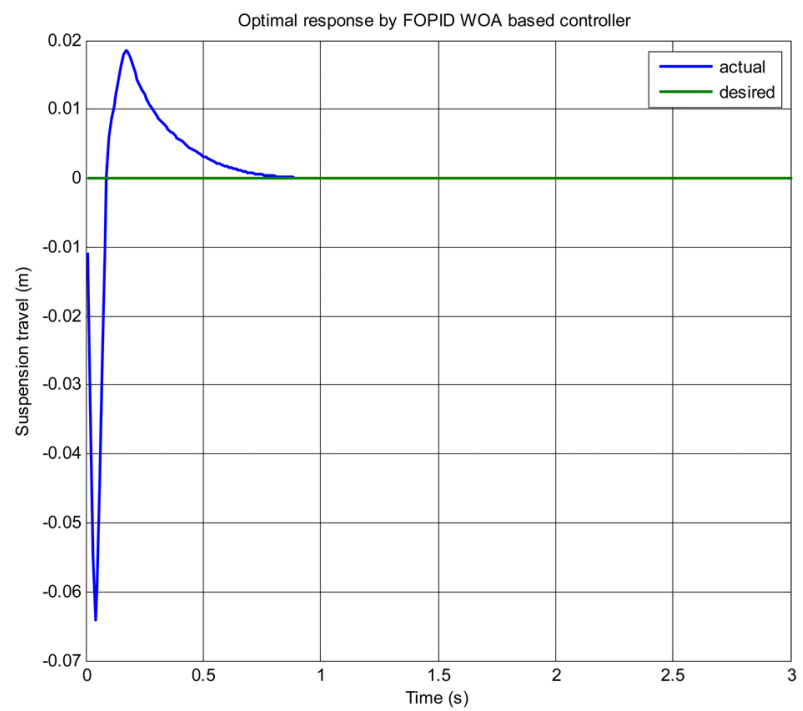

Fig.19 Car body displacement for road input $Z r t=0.1 \mathrm{~m}$

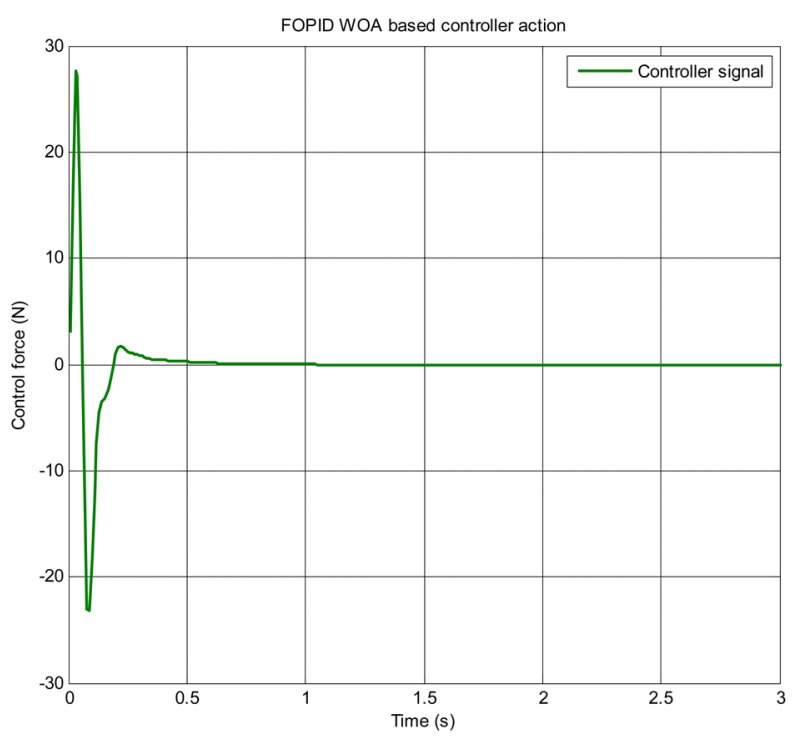

Fig.20 FOPID-WOA based control signal

From the results of Table 2, Table 4, Table 6, and Table 8 it can be concluded that the best controller for the active suspension system is the FOPID controller when tuned using the WOA algorithm. The large percentage of enhancement in the active suspension system appears dynamically in its overshoot and settling time in comparison with the other controllers. The dynamic of the spring-mass displacement and acceleration are shown in Fig. 21 and Fig. 22, respectively. The wheel travel displacement response for the car is shown in Fig. 23.

\section{Percentage of enhancement in system performance}

All the results of the proposed controllers presented in section 6 of this article are compared with previous work [5] 


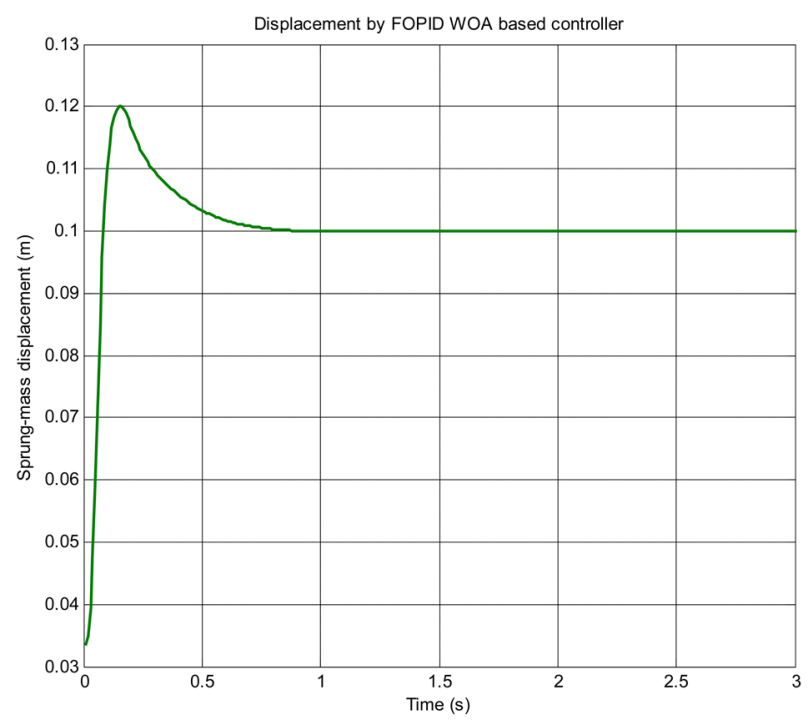

Fig. 21 Car Suspension system deflection (Sprung-mass displacement) for road input $\mathrm{Zrt}=0.1 \mathrm{~m}$

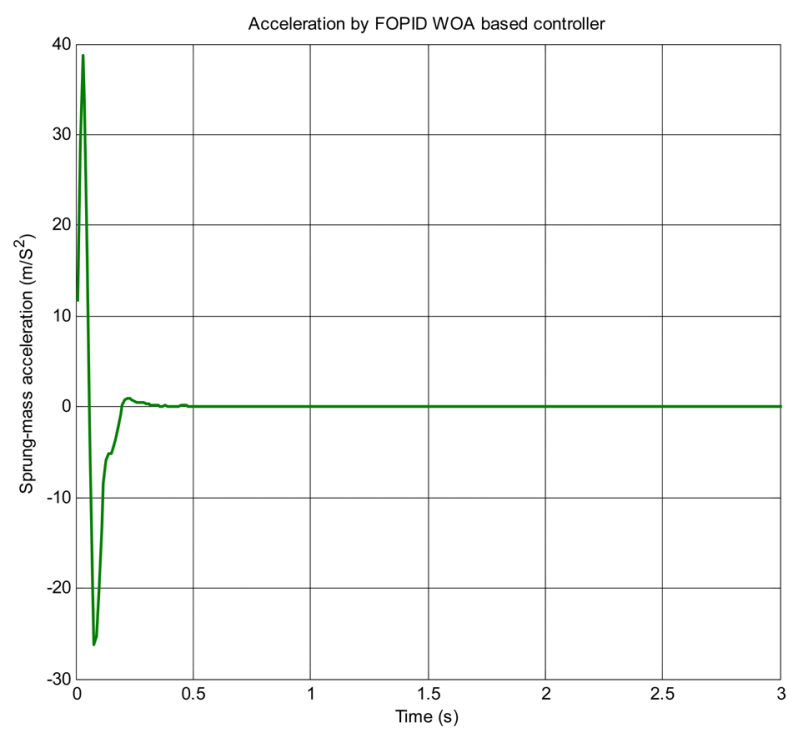

Fig. 22 Car Suspension system acceleration (Sprung-mass acceleration) for road input $Z r t=0.1 \mathrm{~m}$

as given in Table 10. The main compaction factors are in the objective of minimized settling time and overshoot of the suspension travel deflection. These two factors are considered very important as the improvement in an overshoot of the suspension travel deflection will eventually lead to increased stability in driving after exposure to road disturbances. The settling time plays a pivotal role in the ride stability with a faster response. The improved factors cause a comfortable trip and holed drive.

From the above table, it is evident that the FOPID controller when tuned by the PSO or WOA algorithm gives a remarkable enhancement in the measured factors.

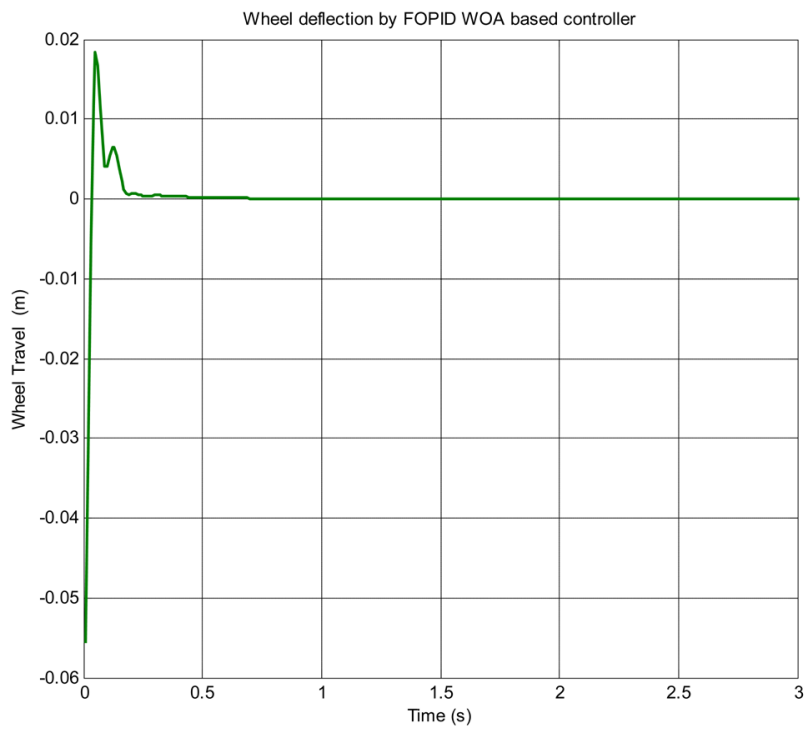

Fig. 23 Wheel Travel for the road input $Z r t=0.1 \mathrm{~m}$

Table 10 Enhanced Controlled system characteristics for all proposed controllers compared with [5]

\begin{tabular}{|c|c|c|c|c|}
\hline \multirow[b]{2}{*}{ Control method } & \multirow[b]{2}{*}{$M p(\mathrm{~m})$} & \multirow{2}{*}{$\begin{array}{c}\text { Settling } \\
\text { Time } t_{S} \\
\text { (sec) }\end{array}$} & \multicolumn{2}{|c|}{$\begin{array}{c}\text { Percentage of enhancement } \\
\text { over [5] }\end{array}$} \\
\hline & & & $M p(\mathrm{~m})$ & $\begin{array}{c}\text { Settling Time } t_{S} \\
(\mathrm{sec})\end{array}$ \\
\hline $\begin{array}{l}\text { PID tuner of } \\
\text { MATLAB }\end{array}$ & 0.02800 & 0.92 & & \\
\hline PID-PSO based & 0.02442 & 1.23 & $12.785 \%$ & - \\
\hline $\begin{array}{l}\text { PID-WOA } \\
\text { based }\end{array}$ & 0.01504 & 1.57 & $46.285 \%$ & - \\
\hline $\begin{array}{l}\text { FOPID-PSO } \\
\text { based }\end{array}$ & 0.01999 & 0.75 & $28.607 \%$ & $18.478 \%$ \\
\hline $\begin{array}{l}\text { FOPID-WOA } \\
\text { based }\end{array}$ & 0.01640 & 0.83 & $41.428 \%$ & $9.782 \%$ \\
\hline
\end{tabular}

The optimal sets of parameters are obtained when utilizing the FOPID controller tuned by WOA. This optimality comes from the ability of the WOA algorithm in finding global minimum points over the PSO algorithm that results in raising the global fitness finding. Table 11 illustrates

Table 11 The optimal percentage of enhancement between the propose controllers in fitness's

\begin{tabular}{lcc}
\hline Control method & $\begin{array}{c}\text { Optimal Fitness } \\
\text { obtained by } \\
\text { the proposed } \\
\text { controllers }\end{array}$ & $\begin{array}{c}\text { Percentage of enhancement } \\
\text { between the fitness's of } \\
\text { proposed controllers (the } \\
\text { next with the previous one) }\end{array}$ \\
\hline $\begin{array}{l}\text { PID tuner of } \\
\text { MATLAB } \\
\text { PID-PSO based }\end{array}$ & 0.0121 & - \\
PID-WOA based & 0.0055 & $54.545 \%$ \\
FOPID-PSO based & 0.0034 & $29.090 \%$ \\
FOPID-WOA based & 0.0017 & $12.820 \%$ \\
\hline
\end{tabular}


the percentage of enhancement in finesse's by the proposed controllers as optimized using the PSO and WOA algorithms. These enhancements are calculated for each controller in the table in relation to its successor controller.

Fig. 24 shows a comparison for the response of the active suspension travel as the different proposed controllers are applied. It is clear that the active suspension system shows an optimal performance when designed using the FOPID controller and tuned by the WOA.

To ensuring the system performance of the approximated and designed FOPID controller, and the bode analysis obtained based on the refined Oustaloup filter, the filter will use an approximation with $\omega=[0.01,100] \mathrm{rad} / \mathrm{s}$, and order $N=5$. So, via FOPID controller open loop bode characteristic is $G m=13.810 \mathrm{~dB}, \Phi_{m}=70.9$ degree. These results are based on the optimized FOPID controller gains obtained via WOA, as listed in Table 9. Fig. 25 shows the bode characteristics of both controllers.

Finally, the developed controller can be digitally implemented using an appropriate microcontroller. A simple 8-bit Atmel - ATmega8A is one of the best choices in this case, where the microcontroller interfaced to 12-bit analogue-to-digital and digital-to-analogue as external converters by using of the $\mathrm{I}^{2} \mathrm{C}$ interfacing technique.

\section{Robustness test}

The robustness test is very important to many applications. System models are normally inaccurate and prone to approximations for different reasons. It could be due to parameter uncertainty, non-modelled elements, or nonlinearities, ageing in components. In addition, modelling might

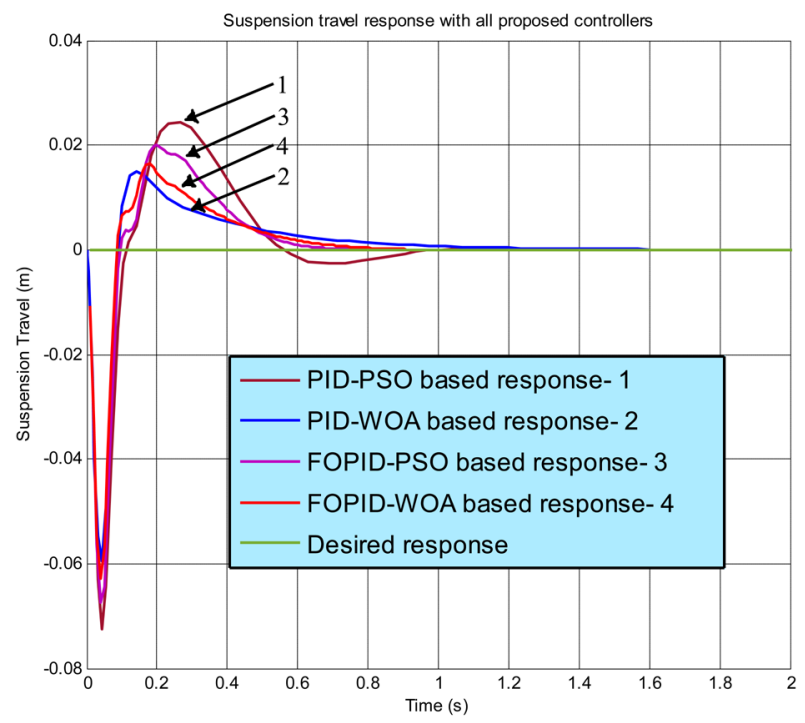

Fig. 24 Car body displacement for road input $Z r t=0.1 \mathrm{~m}$

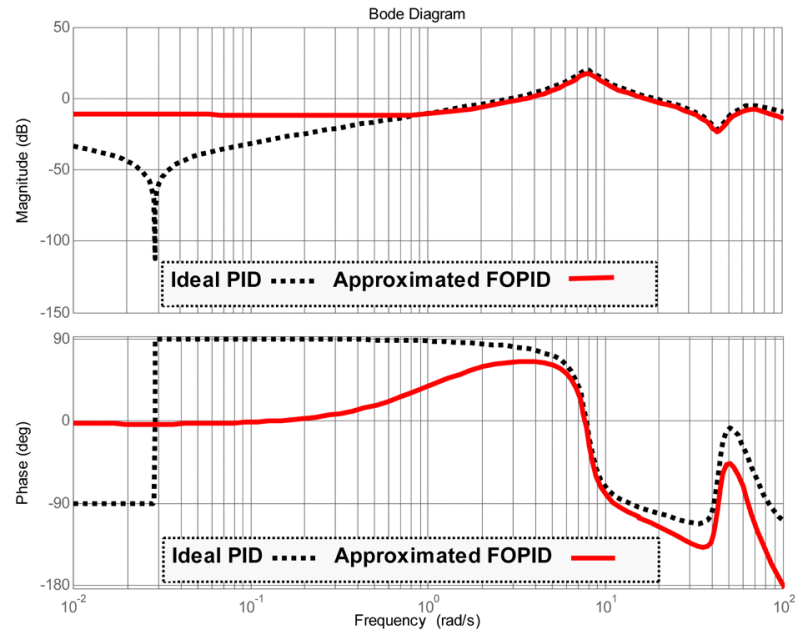

Fig. 25 Open-loop frequency response characteristics comparison for the controlled system

be difficult to conduct, or even sometimes impossible. If the robustness of the FOPID controller is proved, then it tends to keep the suspension system to perform dynamically in an optimum way. This eventually increases the system stability in riding, in addition to comfort travelling incipit of exposure to external road disturbances. The substantially achieves a raise and stable ride. The robustness can be tested for the control systems via simulation, by introducing some plant and controller parameters variations.

\subsection{Parameter variations in the suspension system}

The variation in plant parameters are examined by monitoring the system dynamic characteristics not exceeding a change of $\pm 1 \%$ percent. According to this criterion, it is found that the system model parameter variation limit of $\pm 12 \%$ out of its nominal values will keep its dynamic characteristics unchanged. When the input rode disturbance become $0.2 \mathrm{~m}$ (doubled), the performance of the suspension system with the FOPID controller under the effect of model parameter variations still acceptable, as illustrated in Fig. 26.

The settling time and the overshoot values stay in a range of values resulted using FOPID-WOA based controller, as mentioned in Table 10, with the position response staying unaffected, the same way as shown in Fig. 21.

\subsection{Parameter variations in the FOPID controller}

The controller of the active suspension system can be affected by the external circumstances of the car, specifically due to inaccurate components comprising the designed controller and/or due to the heat that may directly affect the electronics working. The variation in controller parameters is also 


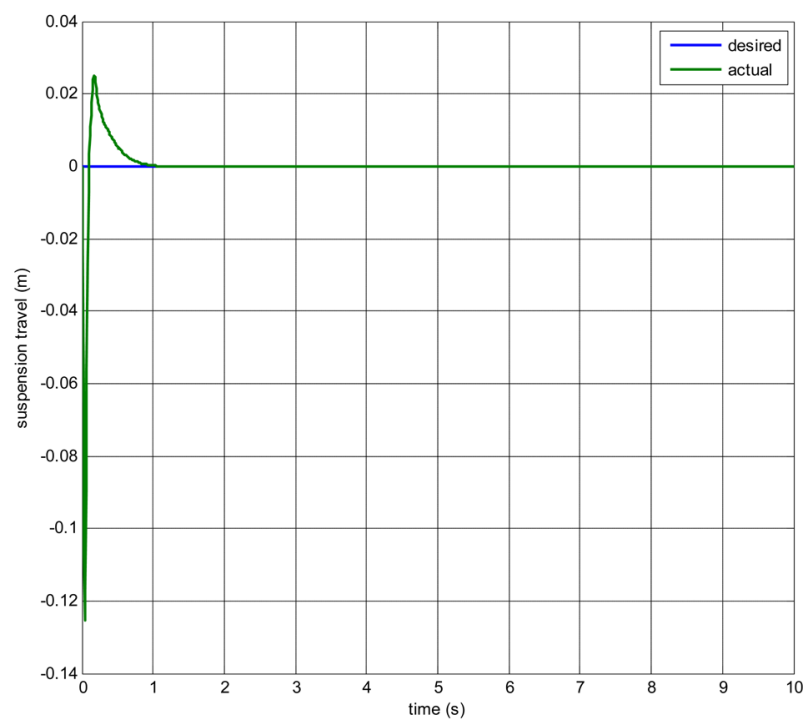

Fig. 26 Active suspension system with $\pm 12 \%$ variation in all system parameters, for input of $Z r t=0.2 \mathrm{~m}$

emulated via changing one parameter at a time to determine the limit of variation that will keep the dynamics unchanged within $\pm 1 \%$. Table 12 illustrates these boundaries of variation for each controller parameter.

The settling time and the overshoot values stay in the acceptable range shown in Table 10. The characteristics of the position response of the active suspension system with the FOPID-WOA controller stays bounded by $\pm 1 \%$ as presented in Fig. 19 in spite of any variations in the controller parameters as given by Table 12 .

\section{Conclusion}

To improve the performance of an active suspension system, aiming at improving the ride comfort and road holding ability, it is noticed that there are other factors that need to be considered for raising the car holding and stability in the road with comfortable passenger travelling. In this paper, the minimum car body displacement and minimum oscillation time after exposing to road disturbances

\section{References}

[1] Kumar, M. S. "Development of Active Suspension System for Automobiles using PID Controller", In: World Congress on Engineering, London, UK, 2008, pp. 1472-1477. [online] Available at: http://www.iaeng.org/publication/WCE2008/ [Accessed: 09 June 2019]

[2] Aldair, A. A., Wang, W. J. "Design of Fractional Order Controller Based on Evolutionary Algorithm for a Full Vehicle Nonlinear Active Suspension Systems", International Journal of Control and Automation, 3(4), pp. 33-46, 2010. [online] Available at: http://article.nadiapub.com/IJCA/vol3_no4/4.pdf [Accessed: 13 March 2019]
Table 12 Maximum limit of variation in FOPID-WOA controller parameters without affecting the active suspension system dynamics

\begin{tabular}{lcc}
\hline $\begin{array}{l}\text { Controller } \\
\text { parameter }\end{array}$ & $\begin{array}{c}\text { Optimal response values obtained } \\
\text { by WOA }\end{array}$ & $\begin{array}{c}\text { Percentage of } \\
\text { change }\end{array}$ \\
\hline$K_{p}$ & 0.9521 & $\pm 66 \%$ \\
$K_{i}$ & 14.69326 & $\pm 14.285 \%$ \\
$\lambda$ & 0.059421 & $\pm 80 \%$ \\
$K_{d}$ & 13.8755 & $\pm 7.142 \%$ \\
$\mu$ & 1.0585 & $\pm 1.904 \%$ \\
\hline
\end{tabular}

(cusp or holes) are proved to contribute to raising the car holding and stability. An optimum robust controller for an active quarter car suspension system is designed for the presented goals. Minimizing the displacement of the car body and reducing the damping frequency of oscillation time are achieved via a nonlinear control strategy using the FOPID controller. The FOPID controller is designed based on PSO and WOA and shown to produce an optimized controller that maintains these characteristics. The parameters tuning of FOPID controller for the active suspension system by using WOA has better characteristics than that reached by the PSO. Robustness of the FOPID controller is examined and proved to withstand a system parameter variation of $\pm 12 \%$ in all system parameters and of maximum of $\pm 80 \%$ in controller parameter changing. A simulation outcome also indicates a considerably improved performance of the FOPID based WOA controller in comparison to the traditional PID one. The FOPID controller provides a faster speed response of the suspension system with smaller overshoot, shorter setting time, and shorter rise time than the PID controller does. In real practical engineering applications, the factor of overshoot is the most concerning one of all parameters. The controller that can provide a small overshoot and shorter settling time in system response can ensure the minimum car displacement and oscillation after exposing to road disturbances.

[3] Pekgökgöz, R. K., Gürel, M. A., Bilgehan, M., Kısa, M. "Active Suspension of Cars Using Fuzzy Logic Controller Optimized by Genetic Algorithm", International Journal of Engineering and Applied Sciences, 2(4), pp. 27-37, 2010. [online] Available at: https:// dergipark.org.tr/ijeas/issue/23576/251137 [Accessed: 25 March 2019]

[4] Nagarkar, M. P., Vikhe, G. J., Borole, K. R., Nandedkar, V. M. "Active Control of Quarter-car Suspension System Using Linear Quadratic Regulator", International Journal of Automotive and Mechanical Engineering (IJAME), 3, pp. 364-372, 2011. https://doi.org/10.15282/ijame.3.2011.11.0030 
[5] Mouleeswaran, S. "Design and Development of PID ControllerBased Active Suspension System for Automobiles", In: Vagia, M. (ed.) PID Controller Design Approaches: Theory, Tuning and Application to Frontier Areas, IntechOpen, Rijeka, Croatia, 2012, pp. 71-98.

https://doi.org/10.5772/32611

[6] Goga, V., Klúčik, M. "Optimization of Vehicle Suspension Parameters with use of Evolutionary Computation", Procedia Engineering, 48, pp. 174-179, 2012.

https://doi.org/10.1016/j.proeng.2012.09.502

[7] Aly, A. A., Salem, F. A. "Vehicle Suspension Systems Control: A Review", International Journal of Control, Automation and Systems, 2(2), pp. 46-54, 2013. [online] Available at: http://researchpub.org/journal/jac/number/vol2-no2/vol2-no2-6.pdf [Accessed: 02 June 2019]

[8] Sun, W., Gao, H., Yao, B. "Adaptive Robust Vibration Control of Full-Car Active Suspensions With Electrohydraulic Actuators", IEEE Transactions on Control Systems Technology, 21(6), pp. $2417-2422,2013$

https://doi.org/10.1109/TCST.2012.2237174

[9] Sun, W., Pan, H., Gao, H. "Filter-Based Adaptive Vibration Control for Active Vehicle Suspensions with Electrohydraulic Actuators", IEEE Transactions on Vehicular Technology, 65(6), pp. 4619-4626, 2016. https://doi.org/10.1109/TVT.2015.2437455

[10] Yao, J., Shi, W., Zheng, J., Zhou, H. "Development of a sliding mode controller for semi-active vehicle suspensions", Journal of Vibration and Control, 19(8), pp. 1152-1160, 2013. https://doi.org/10.1177/1077546312441045

[11] Guo, L.-X., Zhang, L.-P. "Robust $\mathrm{H}_{\infty}$ control of active vehicle suspension under non-stationary running", Journal of Sound and Vibration, 331(26), pp. 5824-5837, 2012. https://doi.org/10.1016/j.jsv.2012.07.042

[12] Wang, R., Jing, H., Karimi, H. R., Chen, N. "Robust fault-tolerant $H_{\infty}$ control of active suspension systems with finite-frequency constraint", Mechanical Systems and Signal Processing, 62-63, pp. 341-355, 2015. https://doi.org/10.1016/j.ymssp.2015.01.015

[13] Ozer, H. O., Sayin, A., Korkmaz, N., Yagiz, N. "Genetic Algorithm Integrated Sliding Mode Control of a Vehicle", In: 11th World Congress on Computational Mechanics (WCCM XI), Barcelona, Spain, 2014, pp. 3857-3868. [online] Available at: http://www. cimne.com/compdesmat/vpage/1/0/Downloads/Conferenceproceedings-and-extended-abstracts [Accessed: 15 January 2019]

[14] Drehmer, L. R. C., Paucar Casas, W. J., Gomes, H. M. "Parameters optimization of a vehicle suspension system using a particle swarm optimization algorithm", Vehicle System Dynamics: International Journal of Vehicle Mechanics and Mobility, 53(4), pp. 449-474, 2015. https://doi.org/10.1080/00423114.2014.1002503

[15] Dong, X., Zhao, D., Yang, B., Han, C. "Fractional-order control of active suspension actuator based on parallel adaptive clonal selection algorithm", Journal of Mechanical Science and Technology, 30(6), pp. 2769-2781, 2016.

https://doi.org/10.1007/s12206-016-0538-2
[16] Deshpande, V. S., Shendge, P. D., Phadke, S. B. "Dual objective active suspension system based on a novel nonlinear disturbance compensator", Vehicle System Dynamics: International Journal of Vehicle Mechanics and Mobility, 54(9), pp. 1269-1290, 2016. https://doi.org/10.1080/00423114.2016.1198490

[17] Concilio, A., De Simone, M. C., Rivera, Z. B., Guida, D. "Razvoj i implementacija sistema upravljanja kod rekonstruisane CNC mašine primenom Arduino platforme" (A new semi-active suspension system for racing vehicles), FME Transactions, 45(4), pp. 578584, 2017. (in Bosnian) https://doi.org/doi:10.5937/fmet1704578C

[18] Fu, Z.-J, Li, B., Ning, X.-B., Xie, W.-D. "Online Adaptive Optimal Control of Vehicle Active Suspension Systems Using SingleNetwork Approximate Dynamic Programming", Mathematical Problems in Engineering, 2017, Article ID: 4575926, 2017. https://doi.org/10.1155/2017/4575926

[19] Xue, W., Li, K., Chen, Q., Liu, G. "Mixed FTS/H$H_{\infty}$ control of vehicle active suspensions with shock road disturbance", Vehicle System Dynamics: International Journal of Vehicle Mechanics and Mobility, 57(6), pp.841-854, 2018. https://doi.org/10.1080/00423114.2018.1490023

[20] Podlubny, I. "Fractional-Order Systems and PI $D^{\mu}$-Controllers", IEEE Transactions on Automatic Control, 44(1), pp. 208-214, 1999. https://doi.org/10.1109/9.739144

[21] Tepljakov, A., Petlenkov, E., Belikov, J., Astapov, S. "Tuning and Digital Implementation of a Fractional-Order PD Controller for a Position Servo", International Journal of Microelectronics and Computer Science, 4(3), pp. 116-123, 2013. [online] Available at: https://yadda.icm.edu.pl/baztech/element/bwmetal.element. baztech-9b74550a-6a22-44cc-8486-f0691fccaa73/c/Tepljakov_ Petlenkov_Belikov_Astapov_Tuning_3_2013.pdf [Accessed: 27 March 2019]

[22] Taher, S. A., Hajiakbari Fini, M., Falahati Aliabadi, S. "Fractional order PID controller design for LFC in electric power systems using imperialist competitive algorithm", Ain Shams Engineering Journal, 5(1), pp. 121-135, 2014. https://doi.org/10.1016/j.asej.2013.07.006

[23] Tepljakov, A., Petlenkov, E., Belikov, J. "A Flexible MATLAB Tool for Optimal Fractional-order PID Controller Design Subject to Specifications", In: Proceedings of the 31st Chinese Control Conference, Hefei, China, 2012, pp. 4698-4703. [online] Available at: https://ieeexplore.ieee.org/document/6390753 [Accessed: 27 January 2019]

[24] Choudhary, S. K. "Stability and Performance Analysis of Fractional Order Control Systems", Wseas Transactions on Systems and Control, 9(45), pp. 438-444, 2014. [online] Available at: http:// eprints.manipal.edu/id/eprint/141489 [Accessed: 05 February 2019]

[25] Anantachaisilp, P., Lin, Z. "Fractional Order PID Control of Rotor Suspension by Active Magnetic Bearings", Actuators, 6(1), Article number: 4, 2017. https://doi.org/10.3390/act6010004 
[26] Hassan, M. Y., Karam, Z. A. "Force-Position Controller Design for 4 Dof's Rehabilitation Robot Arm using PSO Algorithm", International Journal of Information Technology and Business Management, 39(1), pp. 84-98, 2015. Available at: https://www.jitbm.com/JITBM\%20 39th\%20volume/7\%20REHABILITATION\%20ROBOT\%20ARM. pdf [Accessed: 24 March 2019]

[27] Alfi, A., Fateh, M. M. "Identification of nonlinear systems using modified particle swarm optimization: a hydraulic suspension system", Vehicle System Dynamics: International Journal of Vehicle Mechanics and Mobility, 49(6), pp. 871-887, 2011.

https://doi.org/10.1080/00423114.2010.497842

[28] Chen, J., Qin, Z., Liu, Y., Lu, J. "Particle Swarm Optimization with Local Search", In: 2005 International Conference on Neural Networks and Brain, Beijing, China, 2005, pp. 481-484.

https://doi.org/10.1109/ICNNB.2005.1614658

[29] He, Y., Liu, K. "A Modified Particle Swarm Optimization for Solving Global Optimization Problems", In: 2006 International Conference on Machine Learning and Cybernetics, Dalian, China, 2006, pp. 2173-2177.

https://doi.org/10.1109/ICMLC.2006.258615
[30] MathWorks "Genetic Algorithm and Direct Search Toolbox", The MathWorks, Inc., Natick, MA, USA, 2004. [online] Available at: http://cda.psych.uiuc.edu/matlab_pdf/gads_tb.pdf [Accessed: 26 December 2018]

[31] Mirjalili, S., Lewis, A. "The Whale Optimization Algorithm", Advances in Engineering Software, 95, pp. 51-67, 2016. https://doi.org/10.1016/j.advengsoft.2016.01.008

[32] Mafarja,M.M., Mirjalili, S. "HybridWhaleOptimization Algorithm with simulated annealing for feature selection", Neurocomputing, 260, pp. 302-312, 2017.

https://doi.org/10.1016/j.neucom.2017.04.053

[33] Karam, Z. A., Ghintab, S. S., Hasan, S. "Rapidly-implementable optimizely-sizable fuzzy controller architectures: A performance analysis for semiconductor packaging two axes table", Periodicals of Engineering and Natural Sciences, 7(2), pp. 644-659, 2019. https://doi.org/10.21533/pen.v7i2.548 